\title{
Assessment of users' satisfaction in physiotherapy service
}

\author{
Franciele Santos de Oliveira', Aline Braga G. Silveira Fernandes'1, Caio Alano de Almeida Lins'1, \\ Rodrigo Scattone da Silva', Núbia Maria Freire Vieira Lima', Marcelo Cardoso de Souza'
}

\begin{abstract}
Introduction: Satisfaction of the health service user involves multiple factors and dimensions beyond the eminently clinical setting and is inserted in the process of evaluation of health services. It is known that the patient as a source of opinions and suggestions, assists in the process of improving the services offered. Objective: The aim of this study was to evaluate the satisfaction of patients followed in Physical Therapy. Method: It is a cross-sectional descriptive observational research with quantitative and qualitative approach. Two questionnaires (MedRisk and instrument for measuring patient satisfaction with physical therapy in the public health system) were applied in 100 patients. Dimensions were evaluated related to therapist/patient relationship, consultation marking, physical environment, access physical structure and global items. Results: The sample was characterized by the predominance of female users, school graduated and with family income between one and three minimum wages. Most were answered in orthopedics, neurology and rheumatology. 45 objective questions were applied and 42 prevailed at the maximum score. Conclusion: Through the analysis, it was found that the patients mostly were satisfied with the service offered.
\end{abstract}

Keywords: Physiotherapy; Attendance; Satisfaction

\section{INTRODUCTION}

The Clinic School of Physiotherapy of the Faculty of Health Sciences of Trairi (FACISA), campus of the Federal University of Rio Grande do Norte (UFRN), located in Santa Cruz - RN, is a sector of the university created for the academics of the Course of Physiotherapy to develop activities of teaching, research and university extension.

The service receives patients with physiotherapeutic treatment needs in the areas of cardiorespiratory, angiology, health of women, health of child, orthopedics, rheumatology and neurology. In addition, students perform physiotherapeutic assessments and treatments to users under the supervision of teachers.

The concept of health evaluation emerged by strengthening the claims movements for better conditions in the care provided by the health services. ${ }^{(1)}$ One study revealed that early research in the field of health assessment in the 1970s referred to patient satisfaction. ${ }^{(2)}$ However, user satisfaction surveys became more common in the 1990s. ${ }^{(3)}$

The satisfaction of the health service user involves several factors and dimensions that exceed the eminently clinical scope ${ }^{(4)}$ and is part of the evaluation process of health services. It is known that the patient as a source of opinions and suggestions, helps in the process of improvement of the services offered. ${ }^{(5)}$
To evaluate user satisfaction with physiotherapy, it was necessary to create specific questionnaires, since the profession presents a series of factors that influence patient satisfaction, such as the time of service and interaction with the patient, due to their longer duration, besides the therapy involve greater physical contact and the active participation of the patient. In addition, therapy can cause pain and be seen as a physical threat, according to the thoughts of some patients.

At the turn of the 20th century, Rousch and Sonstroem ${ }^{(6)}$ were the first to begin this type of study. One year later, researchers in the United States proposed another measure of satisfaction with physiotherapy. ${ }^{(7)}$

In Brazil, the pioneering work in this line of research is linked to the Department of Physiotherapy of the Federal University of Rio Grande do Norte. Mendonça, in 2004, validated an instrument to be applied in the private health network. ${ }^{(8)}$ Posteriorly, Mendonça and Guerra, in 2007, developed and validated another instrument, but still restricted to the private network. ${ }^{(9)}$

In 2007, Moreira et al. developed and validated an instrument to measure patient satisfaction with outpatient physiotherapeutic care, this time aimed at the public health service. ${ }^{(10)}$ 
Recently, another questionnaire called MedRisk, ${ }^{(11)}$ was translated and validated into Brazilian Portuguese, with the specific objective of evaluating the level of satisfaction of patients with physiotherapy care in Brazil. ${ }^{(12)}$

In any health area, the satisfaction level of health users has been considered an excellent indicator of quality of care. ${ }^{(13)}$

In this sense, the present study aims to evaluate the satisfaction of the patients attended at the Clinical School of Physiotherapy of the Faculty of Health Sciences at Trairi - Federal University of Rio Grande do Norte (FACISA/UFRN), Santa Cruz/RN.

\section{METHODS}

The research was characterized as an observational, descriptive, cross-sectional study with quantitative and qualitative approach.

The sample was for convenience and constituted of 100 users attended in the service of Physiotherapy. The individuals were in care in the areas of cardiorespiratory, angiology, orthopedics, rheumatology, neurology and/or women's health.

The study began after approval by the Research Ethics Committee of the FACISA/UFRN (number CEP 1.245.070). Were followed the principles of bioethics recorded in the resolution $466 / 2012$ of the National Health Council of the Ministry of Health, on research involving human beings.

Users of both sexes, older than 18 years, who received physiotherapeutic care for at least five treatment sessions at the institution, with ability to respond to the questionnaires were included. The exclusion criteria were users of the pediatrics sector, patients with speech and communication difficulties, those who did not accept to participate in the study, and did not sign the Informed Consent Form.

The data were collected in a reserved evaluation room by the same evaluator. The patients were informed of the importance of the research, and the evaluation was started after the sign of the Informed Consent Form. The average interview time was approximately 30 minutes. The data collection for the study was performed from September 2015 to May 2016.

Two questionnaires were applied (the Instrument to assess patient satisfaction with physiotherapy assistance in the public health network and the MedRisk), both as an interview.

The Instrument to assess patient satisfaction with physiotherapy assistance in the public health network, developed and validated by Moreira, Borba and Mendonça (2007), contains 11 descriptive and 32 objective questions totaling 43 questions. ${ }^{(10)}$ Within the objective questions, the first 30 items are divided into six dimensions:

o Therapist/patient relationship (16 questions),

o Schedule a consultation (2 questions) o Physical environment (8 questions)

o Access (2 questions)

o Physical structure (2 questions).

Each item was answered on a five-point interval scale. To analyze the responses, values were assigned to them: value 1 to terrible/never, 2 to bad/no, 3 to good/maybe, 4 to great/yes and 5 to excellent/certainly. The last two items of the instrument question about the future intentions of the patient in relation to the service also with five options of answers: never (1), no (2), maybe (3), yes (4) and certainly (5).

The MedRisk questionnaire, in the Portuguese language version, records the sociodemographic characteristics of the participants, such as age, gender and treatment status. It consists of 13 items divided into factors: 5 items in the internal factor (related to the patient-therapist interaction), 6 items in the external factor (not related to the patient-therapist interaction) and 2 global items. Each item is rated on a 5-point Likert scale. The value of the questionnaire ranges from 13 to 65 points, with higher values indicating better indexes. ${ }^{(12)}$

The instrument also has a 9-point Likert scale, ranging from 1 ("much better") to 9 ("much worse") for overall assessment of the patient's current condition. Higher scores represent greater satisfaction. ${ }^{(12)}$

\section{STATISTICAL ANALYSIS}

Statistical analysis was performed using the Statistical Package for the Social Science (SPSS) software version 20.0. The descriptive statistics for the characterization of the sample and the results were performed according to the type of variable studied. The categorical variables were expressed using percentage values and the values of means and standard deviation were used for the quantitative variables. No normality test was used.

\section{RESULTS}

Table 1 summarizes the sociodemographic data of the individuals. A total of 100 users with a mean age of $50( \pm 15.1)$ years, with $79 \%$ of female.

Of the 100 interviewed users, two underwent treatment in two different areas of physiotherapy during the week.

Noting that $47 \%$ of the patients had already been in the institution for a long time, it was not possible to accurately survey the number of sessions; But they knew the date on which the service began.

The data are detailed in table 1.

The Table 2 summarizes the responses regarding the six dimensions evaluated by the instrument to measure patient satisfaction with physiotherapy assistance in the public health system. 
Table 1. Clinical and socioeconomic characterization of the population attended the Physiotherapy School Clinic FACISA ( $n=100)$.

\section{SOCIODEMOGRAPHIC DATA}

Age

Minimum

Maximum

Mean

18 to 28 years

29 to 38 years

39 to 48 years

49 to 58 years

59 to 68 years

Over

Gender

Man

Woman

Total

Education

Illiterate

Incomplete $1^{\circ}$ degree

Complete $1^{\circ}$ degree

Complete $2^{\circ}$ degree

Graduated

Family income (in minimum wages)

1 to 3

4 to 6

7 to 10

More than 10

Clinical Knowledge

Doctor

Friend

Health Unit

Previous patient

Others

\section{First experience with physiotherapy}

Yes

First experience in this unit

Yes 
Table 1. Continued...

\section{SOCIODEMOGRAPHIC DATA}

Gender of the Therapist

Male

Female

Both

Specialty of the service

Orthopedics

Rheumatology

Neurology

Cardiopneumology

Angiology

Women's Health

Woman

22

17

12

9

12

10
Man

7

2

10

2

0

0

Knowledge of clinical diagnosis

Knows

Does not knows

Number of sessions in this unit

Up to one semester

Second semester in attendance

Third semester in attendance

Fourth semester in attendance

Fifth semester in attendance

Sixth semester in attendance

Table 2. Instrument data to measure patient satisfaction with physical therapy assistance in the public health system ( $\mathrm{n}=100$ ).

\begin{tabular}{|c|c|c|c|c|c|c|c|}
\hline Categorical Variables & Terrible & Bad & Good & Great & Excellent & Yes & Certainly \\
\hline \multicolumn{8}{|l|}{ THERAPIST-PATIENT RELATIONSHIP } \\
\hline 1. Explanations offered by the physiotherapist at first contact. & & $1 \%$ & $12 \%$ & $29 \%$ & $58 \%$ & & \\
\hline 2. Safety transmitted by the physiotherapist during treatment. & & & $10 \%$ & $24 \%$ & $66 \%$ & & \\
\hline 3. Respect and interest with which you are treated by the physiotherapist. & & & $7 \%$ & $20 \%$ & $73 \%$ & & \\
\hline 4. Kindness of the physiotherapist. & & & $2 \%$ & $27 \%$ & $71 \%$ & & \\
\hline 5. Privacy respected during your session. & & & $7 \%$ & $18 \%$ & $75 \%$ & & \\
\hline 6. Clarification of your doubts by the physiotherapist. & & & $8 \%$ & $35 \%$ & $57 \%$ & & \\
\hline 7. Trust in the guidelines given by the physiotherapist. & & & $7 \%$ & $26 \%$ & $67 \%$ & & \\
\hline 8. Attention given to your complaints. & & & $2 \%$ & $20 \%$ & $78 \%$ & & \\
\hline $\begin{array}{l}\text { 9. Opportunity given by the physiotherapist to express your opinion about } \\
\text { the treatment. }\end{array}$ & & & $8 \%$ & $26 \%$ & $66 \%$ & & \\
\hline 10. Physiotherapist ability during the service. & & & $9 \%$ & $28 \%$ & $63 \%$ & & \\
\hline 11. Kindness and availability of other team members. & & & $10 \%$ & $29 \%$ & $61 \%$ & & \\
\hline 12. Deepening of the physiotherapist in the evaluation of the problem. & & & $7 \%$ & $22 \%$ & $71 \%$ & & \\
\hline 13. Language used by Physiotherapist. & & & $6 \%$ & $32 \%$ & $62 \%$ & & \\
\hline
\end{tabular}


Table 3. Continued...

\begin{tabular}{|c|c|c|c|c|c|c|c|}
\hline Categorical Variables & Terrible & Bad & Good & Great & Excellent & Yes & Certainly \\
\hline 14. Techniques and procedures applied comfortably. & & & $8 \%$ & $34 \%$ & $58 \%$ & & \\
\hline $\begin{array}{l}\text { 15. Cleanliness, hygiene and safety of the equipment/materials used by } \\
\text { the physiotherapist. }\end{array}$ & & & $15 \%$ & $32 \%$ & $53 \%$ & & \\
\hline $\begin{array}{l}\text { 16. Explanations given by the physiotherapist for you to perform the } \\
\text { treatment exercises. }\end{array}$ & & & $10 \%$ & $24 \%$ & $66 \%$ & & \\
\hline \multicolumn{8}{|l|}{ SCHEDULE A CONSULTATION } \\
\hline 17. Ease to schedule the physiotherapy session. & & $2 \%$ & $6 \%$ & $28 \%$ & $64 \%$ & & \\
\hline 18. Ease to start physical therapy treatment. & $2 \%$ & $12 \%$ & $21 \%$ & $17 \%$ & $48 \%$ & & \\
\hline \multicolumn{8}{|l|}{ PHYSICAL ENVIRONMENT } \\
\hline 19. Time spent in the waiting room. & & & $6 \%$ & $17 \%$ & $77 \%$ & & \\
\hline 20. Satisfaction with the number of appointments. & $2 \%$ & $2 \%$ & $29 \%$ & $30 \%$ & $37 \%$ & & \\
\hline 21. Convenient time for the session. & $2 \%$ & $3 \%$ & $13 \%$ & $34 \%$ & $48 \%$ & & \\
\hline 22. Convenience in the location of the health unit. & & & $7 \%$ & $22 \%$ & $71 \%$ & & \\
\hline 23. Ease of transport to the physiotherapy service. & $1 \%$ & $7 \%$ & $28 \%$ & $19 \%$ & $45 \%$ & & \\
\hline 24. Comfort of the environment in which you perform physiotherapy. & & & $9 \%$ & $37 \%$ & $54 \%$ & & \\
\hline 25. Comfort of the waiting room. & & $1 \%$ & $12 \%$ & $34 \%$ & $53 \%$ & & \\
\hline 26. General conditions of the health unit. & & & $6 \%$ & $54 \%$ & $40 \%$ & & \\
\hline \multicolumn{8}{|l|}{ ACCESS } \\
\hline 27. Ease to move within the physiotherapy service. & & $1 \%$ & $13 \%$ & $40 \%$ & $46 \%$ & & \\
\hline 28. Access conditions for people with physical disabilities. & $1 \%$ & $4 \%$ & $30 \%$ & $52 \%$ & $13 \%$ & & \\
\hline \multicolumn{8}{|l|}{ PHYSICAL STRUCTURE } \\
\hline 29. Perform your treatment always with the same physiotherapist. & & $5 \%$ & $38 \%$ & $46 \%$ & $11 \%$ & & \\
\hline 30. Importance of physiotherapy in your recovery. & & $2 \%$ & $7 \%$ & $40 \%$ & $51 \%$ & & \\
\hline \multicolumn{8}{|l|}{ CLINIC RECOMMENDATION/RETURN } \\
\hline 31. Would you return to this unit if you needed physiotherapy again? & & & & & & $5 \%$ & $95 \%$ \\
\hline 32. Would you recommend this service to family or friends? & & & & & & $6 \%$ & $94 \%$ \\
\hline
\end{tabular}

Table 3 shows the data of the MedRisk questionnaire, the time taken to reach therapy, plus five items of internal factor (related to patient-therapist interaction, questions $5,6,8,9$ and 11), six items of external factor (no-related to patient-therapist interaction, questions 1, 2, 3, 4, 7 and 10) and two global items (questions 12 and 13).

\section{DISCUSSION}

It is important to emphasize that the Clinical School of Physiotherapy is a reference service in the Trairi region that serves a significant demand from the surrounding cities. Taking into account the opinion of the patients of the public service, created by the internalization process of the Federal Universities, was very salutary.

The population attended to the clinic is composed mainly by individuals of lower socioeconomic status and there is a predominance of females.

The majority of users (86\%) reported having family income between one and three minimum wages.
Regarding education, there was a low percentage of illiteracy in our study (7\%), different frequency from the study of Machado and Nogueira, in which illiterates predominated (31.1\%) among users of public service. ${ }^{(14)}$

The most prevalent diagnoses in this study were orthopedic diseases (27\%), followed by neurologic (22\%) and rheumatologic (19\%). The findings of Magalhães indicate that the specialties of traumatology are the main causes for the demand for physiotherapy services, followed by the diagnoses of rheumatology. ${ }^{(15)}$ This statement is in agreement with other studies. $^{(14,9)}$

In many studies in which the greatest demand for care was orthopedics, varied the second and third place usually between the care in the specialties of neurology and rheumatology. ${ }^{(1,}$ 13, 16-19)

This study is the first one in Brazil that simultaneously used two specific questionnaires, which evaluate patient satisfaction with physiotherapy. This fact is justified by the fact that the application of both allows a more comprehensive evaluation. 
Table 3. Results of the MedRisk Instrument ( $n=100)$.

\section{MEDRISK INSTRUMENT TO EVALUATION OF THE SATISFACTION OF THE PATIENT WITH THE PHYSIOTHERAPY TREATAMENT}

Time spent to get to the physiotherapy clinic:

\begin{tabular}{lc} 
Less than 15 minutes & $61 \%$ \\
Between 16 and 30 minutes & $36 \%$ \\
Between 31 and 60 minutes & $2 \%$ \\
\hline
\end{tabular}

CATEGORICAL VARIABLES

1. The receptionist was courteous

disagrongly

2. The registration was adequate

3. The waiting room was comfortable (lighting, temperature, furniture)

4. The clinic hours were convenient for me

$1 \%$

\section{Disagree}

$1 \%$

$1 \%$

$2 \%$

5. My physiotherapist explained to me carefully the treatments I received

6. My physiotherapist treated me respectfully

7. The clinic employees were respectful

8. My physiotherapist answered all my questions

9. My physical therapist advised me on ways to avoid future problems

10. The clinic and its facilities were clean

11. My physical therapist provided me detailed instructions on my home exercise program

12. In general, I am completely satisfied with the services I received from my physiotherapist

13. I would return to this clinic for future services or treatment

$1 \%$

\begin{tabular}{|c|c|c|c|c|}
\hline & & $1 \%$ & $10 \%$ & $89 \%$ \\
\hline & & & $19 \%$ & $81 \%$ \\
\hline & $1 \%$ & $3 \%$ & $15 \%$ & $81 \%$ \\
\hline & $1 \%$ & $4 \%$ & $16 \%$ & $79 \%$ \\
\hline $1 \%$ & $2 \%$ & $8 \%$ & $24 \%$ & $65 \%$ \\
\hline & $2 \%$ & $1 \%$ & $12 \%$ & $85 \%$ \\
\hline & & $1 \%$ & $5 \%$ & $94 \%$ \\
\hline
\end{tabular}

How is your current condition compared to how you were before you started your physiotherapeutic treatment?

Extremely better

Much better

Slightly better

$57 \%$

$29 \%$

Very little better

$8 \%$

Same
In the dimension of patient-therapist relation, all items most often achieved the highest score. As well as the score presented in the MedRisk questionnaire (table 3) in the five internal factor items in which the patient-therapist interaction is also evaluated in the questions 5, 6, 8, 9 and 11 .

In the item (first question) "The receptionist was courteous" of the MedRisk instrument was the item with the lowest score, although the patients did not report any disrespect.

In one study, the authors discuss that communication between the therapist and the patient is one of the most relevant aspects when assessing satisfaction, therefore they concluded that the therapist/patient dimension presents the highest correlation with the satisfaction of the user in relation to the service. ${ }^{(10)}$

Patient satisfaction is directly related to the elements that refer to the patient's interaction with his/her therapist. ${ }^{(11)}$ In a study ${ }^{(20)}$ the authors observed that the satisfaction of the patient is related with the capacity which the physiotherapist responds to the patient's questions, provides and clarifies information and shows respect.

In the schedule a consultation dimension, the majority of the patients who reported the difficulty, mainly to start the treatment of physiotherapy, were patients attended in the area of orthopedics and neurology. This variance is due to the great demand of the community. Corroborating with other studies about the evaluation of physiotherapy service, ${ }^{(1,10,14)}$ the dimensions in which the users reported the lowest satisfaction were related to the difficulty in schedule and initiating treatment.

Regarding the physical environment dimension of the clinic, it was verified that the less scored items were related to the satisfaction with the number of visits, but currently, it is unfeasible to offer a greater number of services, due to the high degree of occupation of the Clinic's facilities through the disciplines, research projects and extension.

Some users believe that issues related to the comfort of the waiting room and general conditions of the unit may improve and there have been some suggestions such as the placement of non-slip flooring on the edges of the pool. And the accomplishment of multidisciplinary care would add greater satisfaction to them.

Physiotherapy clinics should be a model, seeking better conditions of use, physical facilities and satisfactory access in 
order to promote well-being and a high level of satisfaction of the public. ${ }^{(14)}$

It can be observed that thirty-eight percent (38\%) of users take between 16 to 60 minutes to go to the Clinic. The ease of transportation, together with the time spent in the waiting room, convenience in the location of the clinic (which is in the center of the city) and time of service were fundamental in the continuity of this patient in his treatment.

Regarding the variables related to access for people with disabilities, the highest percentage of responses were between good and great. Those who chose to score between terrible, bad, good or great, based their arguments on their own difficulties or what they observed when they were in the waiting room or in the place where they performed physiotherapy.

Regarding the continuity of the same physiotherapy student in the care, the most recurrent answers were good and great, those that marked bad, highlighted that they do not bother with the constant exchange of students in their treatment. Those who marked the excellent option, however, had their attachment to the therapist. One study highlighted the importance of continuity of care with the same physiotherapist, concluding that patients who received this follow-up were approximately three times more satisfied than those who received care by more than one professional during their treatment. ${ }^{(20)}$ But this situation is not the reality of a School Clinic that meets a high demand of patients.

In the item about the importance of treatment in patient recovery, 91\% scored between great and excellent, even when their diagnosis was chronic or progressive.

The fact that more than $90 \%$ of the patients feel comfortable in the clinic, to return or even indicate it, suggests a humanistic and professional view in the Clinical School of Physiotherapy, considering that the greater the recommendation or the intention to return, the greater their satisfaction with the service. $^{(21)}$

The answers to the question 12 regarding the overall level of satisfaction in MedRisk questionnaire showed a high level of overall satisfaction (85\%).

Although some authors ${ }^{(1,2,10,16,22)}$ affirm that the fact of the service being well evaluated and consequently a good part of the patients are satisfied, may be due to the low critical and evaluative capacity of the users. In the present study, it was observed that the sample in relation to the degree of study was divided equally, with $52 \%$ of the patients with second degree or more. Being a sample partially different of the majority of the users of the health services from the research already carried out in this sense, with a high level of education and, it is assumed, a more accurate level of demand, in this way, able to critically evaluate the service.

Some referrals from our results can be worked on, with the objective of improving the quality of our service.

\section{CONCLUSION}

The users of this service were satisfied with most of the analyzed dimensions, in addition to claiming that they would return and recommend the Clinic School that provided the physiotherapeutic care. In all dimensions predominated the response characterized as great or excellent.

The results obtained through this study can be used for a constant improvement of the quality of the service, since the users demonstrated their expectations and highlighted the system failures.

\section{AUTHORS' CONTRIBUTIONS}

Franciele Santos de Oliveira: "data collection, final review". Aline Braga, Rodrigo Scattone, Caio Alano, Núbia Lima - "statistical analysis, interpretation of data, final review". Marcelo Cardoso de Souza- "study orientation, final review".

\section{CONFLICT OF INTEREST}

The authors declare that they have no conflicts of interest.

\section{REFERENCES}

1. Fréz AR, Nobre MIRS. Satisfação dos usuários dos serviços ambulatoriais de fisioterapia da rede pública. Fisioterapia em Movimento. 2011; 24 (3): 419-28.

2. Vaitsman J, Andrade GB. Satisfação e responsividade: formas de medir a qualidade e a humanização da assistência à saúde. Ciênc saúde coletiva. 2005; 10(3): 599-633.

3. Machado NP, Nogueira LT. Avaliação da satisfação dos usuários de serviços de fisioterapia. Rev Bras Fisioter. 2008; 12(5):401-8.

4. Brito TA, Cleber SJ, Fernandes MH. "Fatores associados à satisfação dos usuários em serviços de fisioterapia”. Revista Baiana de Saúde Pública. 2013; 36(2): 514-26.

5. Polizer R, D'Innocenzo M. Satisfação do cliente na avaliação da assistência de enfermagem. Revista brasileira de enfermagem. 2006; 59 (4): 548-551.

6. Suda EY, Uemura MD, Velasco E. Avaliação da satisfação dos pacientes atendidos em uma clínica-escola de Fisioterapia de Santo André, SP. Fisioterapia e Pesquisa. 2009; 16(2):126-31.

7. Goldstein MS, Elliott SD, Guccione AA. The development of an instrument to measure satisfaction with physical therapy. Physical Therapy. 2000; 80 (9):853-863.

8. Mendonça KPP. (2004). Satisfação do paciente com a fisioterapia: tradução, adequação cultura e validação de um instrumento de medida. 2004. [Dissertação] Natal: Universidade Federal do Rio Grande do Norte; 2004.

9. Mendonça KMPP, Guerra RO. Desenvolvimento e validação de um instrumento de medida da satisfação do paciente com a fisioterapia. Rev bras Fisioter. 2007; 11(5): 369-76. 10.

10. Moreira CF, Borba JAM, Mendonça KMPP. Instrumento para aferir a satisfação do paciente com a assistência fisioterapêutica na rede pública de saúde. Fisioterapia e Pesquisa. 2007; 14 (3): 37- 43.

11. Beattie PF, Pinto MB, Nelson MK, Nelson R. Patient Satisfaction With Outpatient Physical Therapy: Instrument Validation. Phys Ther. 2002; 82(6):557-565

12. Oliveira NFC, Costa LOP, Maher RCG, Beattie PF, Bie R, Oliveira WM, Azevedo DC, Costa LCM. Measurement Properties of the Brazilian Portuguese Version of the MedRisk Instrument for Measuring Patient Satisfaction With Physical Therapy Care. Journal of orthopaedic \& sports physical therapy. 2013; 44(11): 879-89.

13. de Paula DAG, Chiavegato LD. Avaliação do nível de satisfação em pacientes que recebem atendimento de fisioterapia hospitalar: Estudo transversal. $14^{\circ}$ Conic Semesp. 2014; 2 (suppl):1-9 
14. Machado NP, Nogueira LT. Avaliação da satisfação dos usuários de serviços de fisioterapia. Rev Bras Fisioter. 2008; 12 (5):401-8.

15. MAGALHÃES, MS. Avaliação da assistência fisioterapêutica sob a óptica do usuário. [Dissertação]. Fortaleza: Universidade Federal do Ceará; 2003.

16. Rodrigues RM, Raimundo CB, Silva KC. Satisfação dos usuários dos serviços privados de fisioterapia do município de Campos dos Goytacazes/RJ. Rev Perspectivas Online. 2010; 4 (14):163-180.

17. Matias KFS, DI Alencar TAM, Silva TCD. Análise da satisfação do paciente com a fisioterapia na clínica escola de fisioterapia da UEG-ESEFFEGO. Movimenta. 2011; 4 (1): 19-32.

18. Silva Júnior JF, Araújo SP, Nava AV, Dias RS. Serviço prestado em uma clínica escola: fatores influentes na satisfação dos pacientes. Rev Saúde Pesquisa. 2014; 7(1):129-34.
19. Santos BM, Ferraz RRN, Dias TOS, Neri ASC, Oliveira RS. "Satisfação dos idosos com o atendimento fisioterapêutico ambulatorial em uma clínica universitária como elemento de avaliação do modelo de gestão." Revista de Administração de Roraima-RARR. 2014; 4(2): 4-14.

20. Beattie FP, Turner C, Dowda M, Michener L, Nelson R. The MedRisk instrument for measuring patient satisfaction with physical therapy care: a psychometric analysis. Journal of Orthopaedic \& Sports Physical Therapy. 2005; 35 (1): 24-32.

21. Monnin D, Perneger TV. Scale to measure patient satisfaction with physical therapy. Phys Ther. 2002; 82(7):682-91.

22. De Carvalho VL, DM Cavalcante, Santos LPD, Pereira MD. Satisfação dos pacientes atendidos no estágio curricular de fisioterapia na comunidade. Fisioterapia e Pesquisa. 2013; 20 (4):330-335. 